ISSN e- 2594-1100

en-claves del pensamiento / núm 30 / julio-diciembre / 2021 / e437

https://doi.org/10.46530/ecdp.v0i30.437 ARTÍCULOS

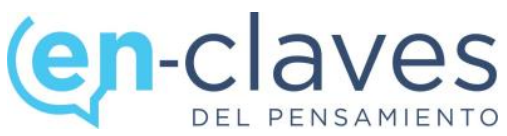

UN COSMOPOLITISMO SIN FUNDAMENTOS ÚLTIMOS ${ }^{1}$

A Cosmopolitanism without Ultimate Foundations

\author{
María Teresa Muñoz Sánchez, Universidad Nacional Autónoma de México, México \\ Correo electrónico: maytemunozsanchez@gmail.com
}

Recibido: $12 / 10 / 2020$

Aceptado: 16/02/2021

Publicado: 01/07/2021

Resumen. Este artículo propone una concepción del cosmopolitismo que prescinde de fundamentos epistémicos o metafísicos. Se trata de lo que he denominado un cosmopolitismo sin fundamentos últimos. El objetivo que se plantea es doble: determinar si existe o se requiere algún fundamento de orden metafísico o filosófico para mostrar la validez del cosmopolitismo como propuesta de orden jurídicopolítico y como ideal de orden moral, por un lado, y, por el otro, una vez demostrado que tal fundamento no se requiere, caracterizar un cosmopolitismo cuya validez no dependa de ningún fundamento último.

Palabras clave: cosmopolitismo, universalismo, humanidad, ciudadanía.

\begin{abstract}
This article proposes a conception of cosmopolitanism that dispenses with epistemic or metaphysical foundations. It is about what I have called a cosmopolitanism without ultimate foundations. The objective is twofold: to determine whether there is or is needed to be sustained on some basis of a metaphysical or philosophical order to show the validity of cosmopolitanism as a proposal of a legalpolitical order and as an ideal of a moral order, on the one hand; and to characterize a cosmopolitanism whose validity depends not on any ultimate foundations, on the other hand.

Keywords: Cosmopolitanism, universalism, humanity, citizenship.
\end{abstract}

Cómo citar: Muñoz Sánchez, M. (2021). Un cosmopolitismo sin fundamentos últimos. En-claves del pensamiento, O(30), e437. doi: https://doi.org/10.46530/ecdp.v0i30.437

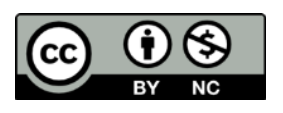

Esta obra está protegida bajo una Licencia

Creative Commons Atribución - No comercial

4.0 Internacional

\footnotetext{
${ }^{1}$ Este texto ha sido realizado en el marco del proyecto internacional El desván de la razón: cultivo de las pasiones, identidades éticas y sociedades digitales. (The dusty attic of reason: the cultivation of the passions, moral identities, and digital societies), PAIDESOC. Proyecto internacional. Centro: Instituto de Filosofía. Organismo: Consejo Superior de Investigaciones Científicas (CSIC) Lider: Concha Roldán.
} 
El lazo entre los hombres es, subjetivamente,

la "voluntad de comunicación sin límite" y, objetivamente, el hecho de la comprensión universal.

Hannah Arendt

Resulta aterrador constatar que una de las mayores paradojas de la política ya manifiesta a inicios del siglo XX sigue siendo de absoluta actualidad, a saber: la incongruencia entre la insistencia general en los derechos humanos inalienables — disfrutados, si acaso, únicamente por algunos ciudadanos de los países más prósperos- y la situación de quienes carecen de tales derechos. A mediados siglo pasado, la filósofa alemana Hannah Arendt demostró con claridad las carencias de esta concepción de los derechos humanos:

[1]os derechos del hombre, después de todo, habían sido definidos como "inalienables" porque se suponía que eran independientes de todos los gobiernos; pero resultó que, en el momento en que los seres humanos carecían de su propio gobierno y tenían que recurrir a sus mínimos derechos, no quedaba ninguna autoridad para protegerles ni ninguna institución que deseara garantizarlos. ${ }^{2}$

Efectivamente, al remitir el cuidado y respeto de los derechos humanos exclusivamente a ámbito de los Estados-nación, se excluye a miles de seres humanos, se les priva del derecho a tener derechos.

No se puede negar que el Estado nación ha servido, en numerosas ocasiones para la defensa de los derechos humanos; sin embargo, la identificación entre la pertenencia comunitaria y la posesión de una nacionalidad o un estatuto legal de ciudadanía ha conducido también a la exclusión y la desatención de los derechos humanos de aquellos que carecen del estatuto legal de ciudadanos "de pleno derecho"; y lo que es más, en los casos más dramáticos como las matanzas y los genocidios, ha devenido en atentados fragrantes contra

\footnotetext{
${ }^{2}$ Hannah Arendt, Los orígenes del totalitarismo, vol. II (Madrid: Alianza Editorial, 1998), 407-408. Para la cita, 414. Véase también, Hannah Arendt, “The Rights of Man: What Are They?”, Modern Review, 3, núm. 1 (1949): 24-36.
} 
los derechos humanos de aquellos a los que por cuestión de raza, etnia o religión se deja de considerar ciudadanos. ${ }^{3}$

Filósofas como Peg Birmingham y Seyla Benhabib ${ }^{4}$ han revalorizado la contribución del pensamiento político arendtiano a la propuesta cosmopolita de los derechos más allá de los límites territoriales del Estado-nación y de su restricción a los "nacionales". 5 En lo que sigue me uniré a su reclamo de "una nueva ley en la Tierra" que garantice el derecho de todos los seres humanos a tener derechos.

Este derecho implica el deber de reconocerse mutuamente como miembros de la comunidad humana y, al mismo tiempo, como ciudadanos protegidos legalmente por las autoridades político-legales. ${ }^{6}$ Desde mi interpretación, el 'derecho a tener derechos' supone fundamentalmente -además de la demanda de derechos jurídico-políticos imprescindibles para el desarrollo de la identidad propia del ciudadano- el reclamo de

${ }^{3}$ De esta problemática ya me ocupé en un trabajo previo donde busqué una reformulación de la idea moderna de derechos humanos que permitiera superar la tensión entre las ideas de ciudadanía, soberanía del Estado y derechos humanos. Para ello me serví de una interpretación del que Arendt propone como derecho fundamental de todo ser humano, el "derecho a tener derechos". véase María Teresa Muñoz, "Ciudadanía, Estado-nación y derechos humanos. Una revisión crítica desde el pensamiento arendtiano", en Luis González Placencia (coord.), Los derechos humanos de los márgenes al centro. Discusiones sobre ciudadanía, política y derechos, vol. 2 (Ubijus / Universidad de Tlaxcala, 2020), 61-90.

${ }^{4}$ Peg Birmingham, Hannah Arendt and Human Rights: The Predicament of Common Responsibility (Bloomington: Indiana University Press, 2006). Existe traducción y a ella recurro, Hannah Arendt y los derechos humanos. El dilema de la responsabilidad común (Buenos Aires: Prometeo, 2017); Seyla Benhabib, The Rights of Others: Aliens, Resident and Citizen (New York: Cambridge University Press, 2004) [Trad. Cast.: Los derechos de los otros. Extranjeros, residentes, ciudadanos, Barcelona: Gedisa, 2005]; Seyla Benhabib, "Otro universalismo: sobre la unidad y diversidad de los derechos humanos", Isegoría (diciembre, 2008): 175-203; y Exile, Statelessness, and Migration: Playing Chess with History from Hannah Arendt to Isaiah Berlin (Princeton: Princeton University Press, 2018).

${ }^{5}$ Nos dice Arendt al respecto: "El resultado de la identificación decimonónica entre nación y Estado es doble: mientras que el estado como institución legal asumía como su deber proteger los derechos de los hombres, su identificación con la nación implicaba la identificación del ciudadano con el nacional, lo que resultaba una confusión de los derechos del hombre con los derechos de los nacionales o con los derechos nacionales". Hannah Arendt, "La Nación", en Ensayos de comprensión 1930-1954. trad. Agustín Serrano de Haro (Madrid: Caparrós Editores, 2005), 255-260, 257 (el énfasis es mío). Reseña de J. T. Delos, La Nación, 2 vosl. Montreal, 1944, en The Review of Politics, VIII, núm. 1 (enero de 1946).

${ }^{6}$ La filósofa Seyla Benhabib propone una defensa de los derechos a partir de un modelo de diálogo moral y político público, libre e igualitario que comparto. No me cabe duda de que su proyecto apunta hacia una revisión del universalismo abstracto, eurocéntrico y patriarcal. Tampoco pongo en duda que en este esfuerzo por reivindicar al otro concreto en política se ha apoyado en una lectura en perspectiva de la obra de Hannah Arendt. Esta reivindicación de un sujeto político concreto deriva en una noción de ética comunicativa o discursiva capaz de proporcionar criterios para repensar la democracia deliberativa. Sin embargo, a mi modo de ver, su deuda con las nociones de ética discursiva y con la teoría de la acción comunicativa le impide llevar su modelo dialógico hasta sus últimas consecuencias asumiendo la contingencia y la incertidumbre de lo político. Esto es lo que me propongo en este artículo. Cfr., Benhabib, Seyla, Los derechos de los otros (Barcelona, Gedisa, 2004), 51.

https://doi.org/10.46530/ecdp.v0i30.437 
una nueva mirada de los derechos que acentúe la idea de que los derechos son capacidades - y no sólo leyes-. Así, en este texto quiero enfatizar que el derecho a tener derechos es un llamado a colocar en primer término la capacidad de existir, de ser en el espacio público. En efecto, la carencia del derecho a tener derechos se manifiesta en la privación de un lugar en el mundo que haga significativas las opiniones y efectivas las acciones. ${ }^{7}$

De modo que continúo aquí las reflexiones previas $^{8}$ y, avanzando más allá del análisis ya elaborado acerca de la paradoja implícita en la noción de ciudadanía, ${ }^{9}$ parto de la propuesta arendtiana - 'el derecho a tener derechos' - con la intención de determinar si es posible conceptualizar este derecho de manera que pueda servirnos como hilo conductor de una renovada noción de cosmopolitismo. En las páginas que siguen voy a centrarme en la caracterización de un cosmopolitismo que no demanda, porque no requiere, fundamentos últimos.

Para dar cuenta de este objetivo dividiré el trabajo en tres partes. En la primera, me ocuparé de analizar el dictum arendtiano 'el derecho a tener derechos', con la finalidad de mostrar el carácter indeterminado del este derecho. Siguiendo a Balibar, sostendré que éste es un derecho sin fundamento a priori, y, sin embargo, es condición de posibilidad de todos los demás derechos. Es desde éste que enfatizaré la idea de los derechos como capacidades. En un segundo apartado, desarrollaré las características que tendría el cosmopolitismo sin fundamentos últimos. Un cosmopolitismo que, pese a su necesario universalismo, no supone la abstracción de los sujetos concretos ni la exclusión de la diversidad. Las categorías arendtianas de pluralidad, sensus communis y juicio reflexionante serán los ejes conceptuales a los que recurriré en mi caracterización de los conceptos de mundo en común y humanidad propios de este cosmopolitismo. En el tercer apartado acudo a la lectura arendtiana del juicio reflexionante kantiano para poder pensar el concepto de cosmopolitismo ligado a la idea de asentimiento general, en lugar de a la validez universal. De este modo, mostraré que mi apuesta no consiste en renunciar a todo

\footnotetext{
${ }^{7}$ Arendt, Los orígenes del totalitarismo, II, 430.

${ }^{8}$ Muñoz, "Ciudadanía, Estado-nación”.

9 A saber: un concepto pensado para proteger a los hombres y mujeres bajo el auspicio de la ley que, simultáneamente en tanto restringido a su vínculo con la soberanía y el estado nación, se finca en la expulsión, la segregación y la exclusión.
} 
posible fundamento, sino en debilitar la noción de manera que se asuma la contingencia de los fundamentos que han de pensarse siempre en plural. Finalmente, en el apartado cuarto, caracterizaré a la humanidad como comunidad de asentimiento. La comunidad humana, entendida como comunidad de asentimiento, se articula —al menos éste es el ideal- a través de prácticas políticas y juicios reflexionantes que ponen el acento en la condición cosmopolita.

Es preciso aclarar que Arendt nunca expuso clara y sistemáticamente sus pensamientos en relación con el cosmopolitismo. ${ }^{10}$ Es cierto que sí se ocupó del Estadonación y de los derechos humanos en Los orígenes del totalitarismo, pero no así en sus obras principales, La condición humana y Sobre la revolución. Los textos donde se ocupó más directamente de una estructura federal mundial y temas relacionados se encuentran en un boceto biográfico de Karl Jaspers — su maestro y mentor - "Karl Jaspers. ¿Ciudadano del mundo?”, y en un breve ensayo sobre Lessing titulado "La humanidad en tiempos de oscuridad. Reflexiones sobre Lessing" (ambos aparecen en Hombres en tiempos de oscuridad); ${ }^{11}$ comentarios breves sobre la necesidad de un tribunal penal internacional permanente en Eichmann en Jerusalem; ${ }^{12}$ una entrevista en la que esbozó "un nuevo concepto del Estado", reimpresa en Crisis de la república; ${ }^{13}$ en las Conferencias, publicadas póstumamente, sobre la filosofía política de Kant, y en algunos ensayos cortos sobre la integración europea recogidos y publicados póstumamente en Ensayos de comprensión.

\footnotetext{
${ }^{10}$ Cfr. Patricia Owens, "Walking Corpses: Arendt on the Limits and the Possibilities of Cosmopolitan Politics", en Cerwyn Moore y Chris Farrands (eds.), International Relations Theory and Philosophy, Interpretive Dialogues (London: Routledge, 2010).

${ }^{11}$ Hannah Arendt, "La humanidad en tiempos de oscuridad. Reflexiones sobre Lessing", y "Karl Jaspers ¿Ciudadano del mundo?", en Hombres en tiempos de oscuridad (Barcelona: Gedisa, 1990).

${ }_{12}$ Hannah Arendt, Eichmann en Jerusalén. Un estudio sobre la banalidad del mal (Barcelona: Lumen, 2003).

${ }^{13}$ Es interesante cómo Arendt en esta entrevista se replantea el concepto de Estado de manera que se pensara como internacional y, no supranacional (las cursivas son de ella), y propone: "Esta forma de Gobierno es el sistema de consejos que, como sabemos, ha perecido cada vez y en cada lugar, destruido, bien directamente por las burocracias de las Naciones-Estados, bien por las maquinarias de partido". Arendt, "Pensamientos sobre política y revolución. Un comentario", en Crisis de la república (Madrid: Taurus, 1998), 232.
} 
En estos materiales se aprecia ciertamente una falta de sistematicidad y la carencia de un fundamento para la acción política. ${ }^{14}$ En efecto, con todo y que Arendt nos abre la puerta a la posibilidad de repensar el ideal cosmopolita desde otra perspectiva, no elabora una concepción teórica ni una reflexión sistemática ni nos ofrece un fundamento filosófico para su idea de un existencia cosmopolita. ${ }^{15}$ Sin embargo, es precisamente su idea de acción política y de capacidad de juicio lo que me permite defender un cosmopolitismo sin fundamentos últimos.

Antes de dar inicio al argumento que deseo desarrollar en este artículo, es necesario ubicar este llamado a pensar el cosmopolitismo sin recurrir a fundamentos externos en el trasfondo de lo que a veces se ha llamado el 'giro ontológico' en el pensamiento acerca de lo político. Se trata de una perspectiva en teoría política surgida a finales del siglo pasado según la cual el pensamiento político dio un cierto giro, para diferenciar lo político de la política. La clave de cada ontología de la política reside en una diferenciación, que ha sido desarrollada por numerosos autores, quienes distinguen entre una política óntica y una ontología de lo político; la primera centrada en el acontecer, en la práctica particular de la política, y la segunda — de carácter más filosófico - centrada en el trasfondo de relaciones sociales complejas que sostiene dicha práctica concreta.

Esta diferenciación se remonta a "La paradoja política" (1955), de Paul Ricoeur, y emergió en la década de los años ochenta con fuerza en pensadores tan diversos como Jean-François Lyotard, Claude Lefort, Alain Badiou, Jacques Rancière y Étienne Balibar. ${ }^{16}$ Este giro ontológico viene acompañado por la radicalización de una postura

\footnotetext{
${ }^{14}$ Filósofas como Seyla Benhabib, Dana Villa y politólogos como Claude Lefort le han hecho duras críticas a su falta de sistematicidad, a la ausencia de un fundamento filosófico moral o jurídico en su filosofía política y a su desinterés en el tema de la justicia. Véase Claude Lefort, Democracy and Political Theory (Minneapolis: Universidad de Minnesota Press, 1988); Dana Villa, Politics, Philosophy, Terror (Princeton: Princeton University Press, 1999), 199.

15 Aunque efectivamente, Arendt no elabora un sistema filosófico, considero en la misma línea interpretativa de Richard Bernstein (véase Richard Bernstein, "Hannah Arendt: The Ambiguities of Theory and Practice", en Terrence Ball (ed.), Political Theory and Praxis: New Perspectives (Minneapolis, University of Minnesota Press, 1977) que en su obra podemos encontrar toda una red de conceptos que conforman un sistema. Se trata — qué duda cabe - de un sistema atípico, pero que puede entenderse como una red que se teje constantemente a lo largo de su obra. Esto es lo que encontramos también en relación con el cosmopolitismo.

${ }^{16}$ Véase Oliver Marchart, El pensamiento político posfundacional. La diferencia política en Nancy, Lefort, Badiou y Laclau (México: Fondo de Cultura Económica, 2009).
} 
teórica que mira al orden social desde una perspectiva posfundacionalista, ${ }^{17}$ contingente y eminentemente política. Es importante señalar que tal propuesta no es equivalente al antifundacionalismo, ya que no se trata de eliminar los fundamentos, sino de debilitar su estatus ontológico. ${ }^{18}$ Como ha señalado Oliver Marchart:

El debilitamiento ontológico del fundamento no conduce al supuesto de la ausencia total de todos los fundamentos, pero sí a suponer la imposibilidad de un fundamento último, lo cual es algo enteramente distinto, pues implica la creciente conciencia, por un lado, de la contingencia y, por el otro, de lo político como el momento de un fundar parcial, y, en definitiva, siempre fallido. ${ }^{19}$

Esta posición posfundacionalista, no antifundamentalista, es la que se recupera y profundiza en este artículo en el contexto de la reflexión sobre el cosmopolitismo.

\section{EI derecho a tener derechos ${ }^{20}$}

El dictum 'El derecho a tener derechos' fue introducido por Arendt en la segunda parte de Los orígenes del totalitarismo, que dedica al tema del imperialismo. En el capítulo nueve, titulado: "La decadencia de la Nación-Estado y el final de los derechos del hombre", podemos leer lo siguiente:

Llegamos a ser conscientes de la existencia de un derecho a tener derechos (y esto significa vivir dentro de un marco donde uno es juzgado por las acciones y las opiniones propias) y de un derecho a pertenecer a algún tipo de comunidad organizada, sólo cuando

\footnotetext{
17 Anabella Di Pego nos ofrece una reflexión que ubica el pensamiento arendtiano precisamente en el contexto de esta postura política. De acuerdo con Di Pego "Lo que Arendt está proponiendo es un desplazamiento o un replanteamiento del problema hacia la posibilidad de pensar una fundamentación sin absolutos", véase Anabella di Pego, "Hacia una política posfundacional: Reconsideraciones en torno de la revolución, la fundación y el poder en Hannah Arendt”, en Marco Estrada y María Teresa Muñoz (comp.), Violencia y revolución en la filosofía de Hannah Arendt (México: Colegio de México, 2015), 109.

18 Agradezco a uno de los revisores anónimos de esta revista haberme empujado a revisar nuevamente el texto de Oliver Marchart. Esto ha dado un giro muy pertinente a mi propuesta inicial: me ha permitido establecer con claridad estos importantes matices entre una filosofía política posfundacionalista y otra, muy distinta, antifundacionalista. De esta vinculación de Arendt con el pensamiento posfundacional ya me ocupé someramente en María Teresa Muñoz, "Violencia y revolución. Reflexiones en torno a lo político", en Estrada y Muñoz (comp.), Violencia y revolución.

${ }^{19}$ Marchart, El pensamiento político posfundacional, 15

${ }^{20}$ En este apartado retomo ideas vertidas en Muñoz, "Ciudadanía, Estado nación".
} 
aparecieron millones de personas que habían perdido y que no podían recobrar estos derechos por obra de la nueva situación política global. ${ }^{21}$

De manera que, el derecho a tener derechos significa vivir dentro de un marco donde uno es juzgado por sus acciones y opiniones. Este marco, dado por lo que Arendt denomina mundo común (de ello me ocuparé un poco más adelante), les es negado a todos aquéllos que no comparten derechos civiles, sociales y culturales bajo el cuidado de un determinado Estado-nación. Y lo que se les está negando es algo más fundamental que el derecho a la libertad o a la igualdad de trato, que son derechos ciudadanos, lo que se les está negando es su pertenencia a una comunidad, a un mundo común. De este modo, se les imposibilita la acción y la opinión, y con ello, como veremos líneas abajo, la posibilidad de constituir su identidad como miembros de mundo común.

En su ensayo de 1951, encontramos un análisis de las condiciones que condujeron al ascenso del totalitarismo, y una fuerte crítica al Estado-nación. Este diagnóstico no lleva a Arendt a pensar en una especie de Estado global; Arendt piensa la ciudadanía en términos de participación política, de manera que es en el marco del Estado-nación que los ciudadanos pueden encontrar este ámbito de participación y, por ello, es en ese espacio compartido en el que los derechos pueden y deben ser garantizados. Ahora bien, para que esto sea el caso es preciso abandonar la idea de que el sujeto de los derechos humanos es el ser humano en abstracto, ése que no podemos ubicar en un lugar concreto en el mundo.

Si bien es cierto que la Declaración de los Derechos del Hombre, proclamada a finales del siglo XVIII, parte de una caracterización del derecho que se encuentra fundamentada por el hombre en última instancia, y no en una divinidad o en un soberano, no obstante, dicha descripción se encuentra lastrada por la abstracción, esto es, parte y se sostiene en una idea Hombre, con mayúsculas y en abstracto. Sin embargo, como se muestra a diario en las fronteras, en las pateras, en las oficinas de migración, etc., son los hombres concretos aquéllos que tendrían que poder actuar y mostrarse en el espacio público, los que requieren del derecho político más básico, a saber, el derecho a tener derechos. Éste es el derecho más básico por ser indeterminado, pues se trata de un

\footnotetext{
${ }^{21}$ Arend, Los orígenes del totalitarismo, II, 430.
} 
derecho político a reivindicar derechos. Es por ello — podríamos decir, con Balibar - un derecho "primero" indeterminado, "y en ningún caso un derecho 'estatutario' particular. En este sentido, se trata de un derecho sin fundamento a priori, tan contingente como lo es la comunidad política ella-misma". ${ }^{22}$ Y más aún, "este derecho a tener derechos es a la vez absoluto y contingente", ${ }^{23}$ absoluto, en tanto que es condición de posibilidad de todos los demás, pero es tan contingente como la propia comunidad política surgida de la acción en el espacio público. ${ }^{24}$

Como ya he expuesto en otros escritos, ${ }^{25}$ a lo largo del siglo $\mathrm{XX}$ se ha venido produciendo un desplazamiento, una identificación entre los derechos civiles y los derechos humanos. Estos últimos deberían ser considerados independientes de la ciudadanía, entendida en términos legales, y la nacionalidad, y, sin embargo, se ha producido una identificación que sujeta los derechos humanos al Estado-nación y a la condición legal de ciudadano. Al identificar la ciudadanía con la condición de sujeto de derechos, y, al mismo tiempo, reducir los derechos humanos a derechos civiles, se excluye a miles de seres humanos, se les priva del derecho a tener derechos. Esta carencia se manifiesta, como veremos más adelante, en la privación de un lugar en el mundo que haga significativas las opiniones y efectivas las acciones. ${ }^{26}$

De acuerdo con la propuesta arendtiana, el derecho a tener derecho sería un mandato moral para no violar el derecho a la humanidad en una persona singular. El derecho a tener derechos lo otorga la humanidad y quién recibe es una persona moral en tanto parte de la humanidad. Así, el derecho a tener derechos trasciende la contingencia de nacimiento o pertenencia a una etnia o nación. Este derecho funciona como condición de posibilidad de todos los demás derechos, que sólo pueden realizarse en una comunidad

\footnotetext{
22 Étienne Balibar, "Impolítica de los derechos humanos. Arendt, "El 'derecho a tener derechos' y la desobediencia cívica", Erytheis, 2 (noviembre de 2007), 6. http://idt.uab.es/erytheis/balibar_es.htm

${ }^{23}$ Ibidem.

${ }^{24}$ Claudia Hilb nos advierte acerca del problema de esta contingencia en una reflexión sobre el origen de la comunidad política, analizando la fundación, o mejor, la legitimidad de la fundación. Para abordar este tema, Hilb discute la noción de principio y nos propone distinguir dos formas en las que aparece en la obra de Arendt: la que denomina "montesquievina", y que remite al principio de acción de un régimen, y otra, a la que nombra la "inaugural", que remite a la institución del nuevo comienzo, a la acción inauguradora. Cfr., "El principio del initium" en Estrada y Muñoz (comp.), Violencia y Revolución.

${ }_{25}$ Véase Múñoz, "Ciudadanía y derechos", Revista UIC Foro Multidisciplinario de la Universidad Intercontinental (octubre-diciembre, 2017), y "Ciudadanía, Estado-nación".

${ }^{26}$ Arendt, Los orígenes del totalitarismo, II, 430
} 
política a la que se pertenece no por razones de raza o nacimiento sino por la participación en la vida pública con acciones y discursos. Siendo así, ¿a qué tipo de cosmopolitismo estamos apelando?

\title{
Un cosmopolitismo sin fundamentos últimos
}

\author{
Lo específicamente humano de la vida humana \\ es que se construye un mundo. \\ Hannah Arendt \\ El mundo está entre las personas, y este estar en \\ el medio es hoy (mucho más que los hombres \\ o incluso el hombre, tal como se piensa) objeto \\ de la mayor preocupación y del trastorno \\ más obvio en casi todos los países del globo. \\ Hannah Arendt
}

Dado que en este texto busco esbozar una nueva mirada al cosmopolitismo, debo comenzar señalando que no se trata de suponer la posibilidad de un gran Estado cuya soberanía descanse en un gran gobierno sobre la Tierra; no se trata de ningún modo de un gobierno global. ${ }^{27}$ Ser ciudadana del mundo no significa para mí ser miembro de una comunidad mundial sometida a un gobierno global único. Y, sin embargo, esto no impide que me considere conciudadana de todos los habitantes de la Tierra existentes, del pasado y del porvenir. De manera que me preocupa la vida de todos ellos y ellas y no sólo la de aquéllos y aquéllas que son integrantes de mi comunidad política. El cosmopolitismo es la preocupación y el interés por la humanidad sin el deseo de un gobierno global.

\footnotetext{
${ }^{27}$ Etienne Tassin señala pertinentemente una diferencia léxica entre mundialización y globalización que le permite, recurriendo al pensamiento arendtiano, criticar el proceso de unificación y homogeneización de conductas y comportamientos que implica la llamada globalización. Comparto, desde luego, la posición de Tassin, quien ha defendido lo que denomina una cosmopolítica que "consiste en establecer, en el seno de cada Estado, de cada comunidad, de cada grupo, de todos, las relaciones con los otros que despliegan un espacio público, en el que todos pueden manifestarse y actuar, de manera que se preserven siempre el principio y la posibilidad fáctica de las manifestaciones y las acciones" Vid., "Hannah Arendt frente a la globalización" en Julia Smola, Claudia Bacci y Paula Hunziker (eds.), Lecturas de Arendt. Diálogos con la literatura, la filosofía y la política, Córdoba, Editorial Brujas, 2012) 207-220. Para la cita, 216. Mi acercamiento al tema del cosmopolitismo consiste, a diferencia de la propuesta de Tassin, en revisar la noción de Humanidad desde la idea de comunidad de asentimiento.
} 
Desde esta posición, el cosmopolitismo es una inquietud de carácter universalista preocupada porque todo ser humano pueda tener una vida digna. Ahora bien, afirmar el deber de procurar una vida digna para todo ser humano, significa un universalismo en el sentido de que estamos pensado en la humanidad como todos los seres existentes, que han existido y que existirán, pero no significa que debamos fincar este universalismo en una uniformidad universal de valores, principios o concepciones del bien, ni siquiera en una mínima expresión de los valores que pudiéramos suponer que compartimos. Se trata, por el contrario, de enfatizar el valor de la diferencia de principios y valores, de poner en valor la condición ontológica de la pluralidad, en términos arendtianos. ${ }^{28}$ En efecto, esta propuesta de cosmopolitismo sin fundamentos últimos es una manera atinada de entender el dictum arendtiano 'el derecho a tener derechos' respetando la condición ontológica de la pluralidad humana.

El dictum arendtiano nos habla de un derecho. ¿Cómo debemos entender esta noción de derecho?, ¿en qué se funda?, ¿requiere un fundamento? Éstas son las preguntas de las que me ocuparé a continuación y que me permitirán exponer mi noción de cosmopolitismo.

Comenzaré preguntándome si existe, más allá de la legalidad recogida en las Constituciones de los Estados o en la Declaración Universal de 1948, algún fundamento epistémico, moral o político para los derechos humanos. El motivo de esta pregunta radica en que, pareciera que, si carecemos de una justificación epistémica, moral o política para los derechos humanos, no podemos establecer su acatamiento universal.

Mi propuesta, siguiendo a Arendt, no requiere de un fundamento a priori para los derechos humanos. Considero, con Posenti, que la propuesta arendtiana supone

una modalidad de articulación de la condición práctica e histórica de los derechos humanos que invierte término a término cierta manera de fundar la política a partir de una esencia metafísica. Sin duda, es esa idea del "sin fondo", la única que puede autorizar una

\footnotetext{
${ }^{28}$ Es importante señalar que, aunque las alusiones a la pluralidad son constantes en su obra, en realidad, Arendt nos ofrece definiciones de ella en contadas ocasiones. Véase Richard Bernstein, "Provocation and appropriation: Hannah Arendt's response to Martin Heidegger", Constellations, 4, núm. 2 (1997). Se trata de una condición ontológica de los seres humanos que habitamos el mundo. Tal como Arendt nos recuerda: "todos somos lo mismo, es decir, humanos, y por tanto nadie es igual a cualquier otro que haya vivido, viva o vivirá". (Hannah Arendt, La condición humana, int. Manuel Cruz, 3er. reimp. [Barcelona: Paidós, 1998], 22). La pluralidad es, pues, esta singularidad constitutiva.
} 
identificación de los derechos humanos con una práctica (o una actividad pura), al precio, no obstante, del reconocimiento de su carácter históricamente contingente o "aleatorio". ${ }^{29}$

Esta manera de entender la articulación de los derechos humanos me parece más atinada, si tenemos en cuenta el énfasis arendtiano en la contingencia. Dicho énfasis es lo que permite a Arendt establecer sus reflexiones en lo que podría interpretarse como un gesto impolítico (Balibar), y lo que ubica sus planeamientos como un antecedente de este giro ontológico posfundacionalista del que hablamos al inicio. En efecto, Arendt establece una distinción ineludible entre una esfera ideal de lo político y la política. El criterio que nos permite distinguir entre ambas categorías tiene que ver con el énfasis arendtiano en la contingencia de la acción política. La política consiste en el conjunto de estrategias de que se sirven las autoridades para el desarrollo de lo social. Se concreta en formas burocráticas, económicas o instrumentales de la racionalidad que suponen el cálculo racional, el conocimiento anticipado de causas y consecuencias. Este modo de caracterizar a la política está cargado de connotaciones negativas: la política así mostrada supone una degeneración de su sentido originario al convertirse en mera administración de los recursos públicos. En cambio, lo político se presenta como el ámbito de la deliberación pública y de la comunalidad en pluralidad. De este modo, Arendt rechaza que lo político pueda fundarse más allá o desde un afuera: “[1]a política, o, para el caso, lo político, no puede fundarse en algo fuera de sí misma, esto es, fuera del espacio intermedio [in- between] o situado entre quienes se reúnen con el objeto de actuar". ${ }^{30}$ Lo político debe ser autónomo de manera que pueda emerger como función instituyente de la sociedad.

En este sentido, volviendo al tema que nos ocupa, efectivamente - tal como le critica Benhabib, entre otros_-, ${ }^{31}$ Arendt no busca establecer un fundamento para los derechos humanos o para la idea de justicia; ella enfatiza el carácter contingente de la acción política y busca destacar el valor de la deliberación pública y de la comunalidad en

\footnotetext{
${ }^{29}$ Ilaria Posenti, L'apolide e il paria. Lo straniero nella filosofia di Hannah Arendt (Roma: Carocci Editore, 2002), 31, 32, 95 y ss. Referida por Étienne Balibar, "Impolítica de los derechos humanos. Arendt, el 'derecho a tener derechos' y la desobediencia cívica", Erytheis, 2 (noviembre, 2007), 3. http://idt.uab.es/erytheis/balibar_es.htm

${ }^{30}$ Marchart El pensamiento político posfundacional, 70

${ }^{31}$ Véase nota 15. 
pluralidad en los procesos de institucionalización, en los momentos de constitución de nuestro mundo común. Se trata de un énfasis en el actuar de común acuerdo, actuar juntos. En el espacio público, una comunidad libre ejerce el poder cuando, mediante las deliberaciones públicas, promueve y protege el bienestar de la comunidad. La justificación del cosmopolitismo desde esta perspectiva no puede ser más que política.

El modelo arendtiano de la acción política supone la imposibilidad de pensar un fundamento último para lo político, un fundamento extrapolítico. Por ello, asume la radical contingencia de lo político. ${ }^{32} \mathrm{Y}$ es desde este posicionamiento de raigambre arendtiana que defiendo una concepción a la que denomino cosmopolitismo sin fundamentos últimos. Un cosmopolitismo que renuncia, y además no requiere, la idea de fundamento más allá del propio ejercicio de la participación en la vida pública de los miembros de la comunidad humana. Arendt, como señalé desde la introducción, no elabora una teoría acerca del cosmopolitismo; ella pone el acento en la condición cosmopolita que debe cultivarse a través de la acción y la palabra.

Si bien es cierto que buscamos hacer una reflexión acerca de este modo de existencia cosmopolita y que, a través de este texto, buscamos hacer una defensa de cosmopolitismo, de lo que se trata es de mostrar, podríamos decir, de ejemplificar este modo de existencia como el más deseable para alcanzar una vida plena para todos y todas, y no de generar una nueva teoría. De esta manera, si bien, desde la reflexión y la defensa de tal cosmopolitismo, aspiro a que los derechos humanos obtengan asentimiento general desde la pluralidad, no pretendo defender de su validez universal.

El concepto de universalismo se ha ligado habitualmente a las nociones de imparcialidad y objetividad comprometidas con un uso de la razón que excluye la pluralidad, anula la posibilidad de pensar a los seres humanos en plural y privilegia al Hombre, así con mayúsculas, en abstracto y singular. Para evitar tal vinculación del cosmopolitismo a un universalismo que suponga abstracción y exclusión de la diversidad acudo a la recuperación del juicio reflexionante kantiano desde la mirada arendtiana. Desde este tipo de juicios se nos abre a la posibilidad de pensar el concepto de

${ }^{32}$ Me he ocupado de este tema en "El retorno de lo político. Acerca de la oposición entre poder y violencia", en Armando Casas y Leticia Flores (Comps.), Relatos de violencia. Acercamientos desde la filosofía, la literatura y el cine (México: Facultad de Filosofía y Letras-UNAM / Centro Universitario de Estudios sobre Cine-UNAM, 2013), 185-206. 
cosmopolitismo ligado a la idea de asentimiento general, en lugar de a la validez universal. De este modo, no se trata de renunciar a todo posible fundamento, sino de debilitar la noción de manera que se asuma la contingencia de los fundamentos que han de pensarse como contingentes y siempre en plural. Entiendo entonces el cosmopolitismo como una práctica política de aplicación universal que supone y que debería reflejarse en un orden político y jurídico. Nótese que dicha práctica no puede pensarse al margen de toda fundamentación, so pena de quedar a expensas de derivas autoritarias, excluyentes e incluso totalitarias. Ciertamente, es preciso establecer algún mecanismo que permita establecer la validez de estas prácticas; dicha validez ha de sostenerse en el ejercicio de la capacidad de juicio de los miembros de la comunidad humana.

De manera que, el universalismo al que estoy apelando aquí a través de la noción de asentimiento general apunta a un tipo validez (una validez para las prácticas políticas que permiten el reconocimiento de todos los seres humanos) en permanente cuestionamiento podríamos decir, en un incierto equilibrio entre el sensus communis ${ }^{33}$ -que permite la comunicabilidad de los juicios compartidos - y la pluralidad, condición ontológica propia de la condición humana. El papel del juicio reflexionante en vínculo con la acción política es lo que me permite afirmar un cosmopolitismo sin fundamentos últimos.

\section{El juicio reflexionante y la comunidad de asentimiento}

Es preciso determinar, en primer término, en qué consiste esta capacidad de juicio a la que podemos apelar para modificar la idea de lo derechos humanos. Recordemos que la idea de derecho apunta tanto al poder o facultad del individuo para reclamar algo de los

\footnotetext{
33 Desarrollaré este concepto más adelante. Sobre la complejidad del sensus communis, véase Alessandro Ferrara, La fuerza del ejemplo. Exploraciones del paradigma del juicio (Barcelona: Gedisa, 2008), especialmente el apartado titulado, "El núcleo del paradigma: el universalismo ejemplar y el sensus communis", 45- 59. Para Ferrara "el sensus communis revisado es esta sabiduría acerca de la evolución de la vida humana, una sabiduría que también puede expresarse en términos de una serie de dimensiones de la realización o la evolución de una identidad y que se basa en un vocabulario situado de alguna manera "antes" o "debajo" de la diferencia de las culturas", 55.
} 
otros, como a la ley o sistema jurídico. ${ }^{34}$ En este escrito me interesa enfatizar la idea del derecho como facultad o poder del individuo, como capacidad.

De acuerdo con la lectura que hace Arendt de la tercera crítica de Kant, en los juicios políticos, se adopta una opinión que, si bien mediada por lo subjetivo — es decir, por el lugar que la persona que juzga ocupa en el mundo compartido-, deriva su validez de la realidad del mundo. Dicha realidad está anclada en el hecho de que mundo es lo común a todos. Y aquí, cuando Arendt habla de mundo, no está pensado en la comunidad cercana sino en la humanidad.

En el mismo tenor, cuando pienso en el cosmopolitismo no parto de los sujetos individuales como poseedores de derechos universales, sino de la pluralidad humana que subyace a la acción política, esa acción que nos permite constituir un mundo en común. Esta acción no puede ser pensada al margen de la capacidad de juicio. No en vano son nuestras acciones y discursos las que nos permiten constituir el mundo en común. Al juzgar, partimos de nuestra condición de ciudadanos singulares y, al mismo tiempo, debemos adoptar una perspectiva cosmopolita más amplia y, en última instancia, mediar entre las dos perspectivas. De esta manera, podemos tomar en serio tanto a nuestros compatriotas como a quienes no lo son. No necesitamos, entonces, apelar a un universalismo de los principios ni de las reglas; requerimos de la capacidad de juicio de los miembros de la comunidad humana en el ejercicio de la acción política en la constitución del mundo compartido. ${ }^{35}$

Cuando Arendt recupera la capacidad de juicio establece una distinción clara entre esta forma de discernimiento capaz de juzgar desde la particularidad, y el pensamiento especulativo que busca la universalidad en abstracto. El pensamiento especulativo trasciende por completo el sentido común mientras que el discernimiento propio del juicio político -y también del estético — se arraiga en ese sentido común que

\footnotetext{
${ }^{34}$ Véase Juan Antonio Cruz Parcero, "Derecho subjetivo", entrada en Carlos Pereda (ed), J. Marcone, M.T. Muñoz y S. Ortiz (coords.), Diccionario de Justicia (México: Siglo XXI, 2017), 150-155.

${ }^{35}$ Aunque comparto el diagnóstico de Tassin acerca de la naturaleza acósmica de los tiempos modernos ofrecida en Le Trésor perdu, Hannah Arendt lîntelligence de l'action politique (Paris, Ed Payot \& Rivages, 1999) y su análisis respecto a la carencia de mundo y la posibilidad de repensar desde dicha carencia un cosmopolitismo, sin embargo, mi énfasis a la hora de pensar la constitución de mundo en común desde una actitud cosmopolita se centra en el papel del juicio reflexionante en el momento de constituir y, al mismo tiempo, partir de un sensus communis y con él una comunidad de asentimiento.
} 
compartimos con los otros al tiempo que compartimos el mundo: el sensus communis. A pesar de las diferencias de juicio, nos reconocemos como miembros de una comunidad. Nótese que "[e]1 juicio [...] se refleja siempre sobre los demás y sus gustos, toma en consideración sus posibles juicios. Esto es necesario porque soy humano y no puedo vivir sin la compañía de otros. Yo juzgo como miembro de esta comunidad y no como miembro de un mundo suprasensible". ${ }^{36}$ Esta pertenencia a la comunidad se hace explícita a través de la noción, recuperada de Kant, de sensus communis, ese sexto sentido que compartimos al tiempo que nuestro mundo en común. Denominado por Arendt sentido comunitario, nos abre a la posibilidad de juzgar con los otros sin perder lo que nos hace únicos, lo que nos distingue de aquellos con los que compartimos juicio. Y este compartir va más allá de la comunidad de pertenencia étnica o nacional: "se juzga siempre como miembro de una comunidad, guiado por un sentido comunitario, un sensus communis. En definitiva, se es miembro de una comunidad mundial por el simple hecho de ser hombre, tal es la "existencia cosmopolita"'.37

$\mathrm{Si}$ bien es cierto que hacer referencia al sensus communis parece conducirnos a pensar en una comunidad de juicio ya instituida, la imaginación y el pensamiento representativo nos permiten apelar a la capacidad de generar nuevos juicios que interpelen y modifiquen los márgenes de la comunidad. ${ }^{38}$ Arendt recuperó la noción kantiana de imaginación [Einbildungskraft] entendiéndola como aquella capacidad que permite al ser humano rebasar las condiciones privadas de su juicio para hacer presentes a los demás interlocutores: la imaginación permite que el individuo sea capaz de ir más allá de sí mismo, de rebasar las condiciones privadas del juicio y ser imparcial frente al objeto o acontecimiento, tomando en cuenta los juicios de los demás interlocutores. De este modo, gracias a la imaginación, aquel o aquella que juzga puede ponerse en el lugar de otro o de la otra. Así, es posible alcanzar un pensamiento representativo: me represento aquellas perspectivas de mundo de los que están ausentes.

\footnotetext{
${ }^{36}$ Hannah Arendt, Conferencias sobre la filosofía política de Kant, int. y ed. Ronald Beiner (México: Paidós, 2003), 126.

${ }^{37}$ Ronald Beiner, "Ensayo interpretativo", en Arendt, Conferencias, 139.

${ }^{38}$ Cfr., Linda Zerilli, "The practice of Judgment: Hannah Arendt's Copernican Revolution", en Jane Elliott y Dereck Atridge (eds.), Theory after Theory (London: Routledge, 2011). 
Desde Kant, la validez de los juicios reflexionantes depende de la posibilidad de pensar poniéndose en el lugar del otro o de la otra. A esto le denomina un pensar representativo. De este modo, un primer aspecto del juicio así entendido que debemos tener presente es su carácter esencialmente representativo: "me formo una opinión tras considerar un determinado tema desde distintos puntos de vista, recordando los criterios de los que están ausentes; es decir, los represento". ${ }^{39}$ Siendo así, podemos repensar gracias al poder creativo de la imaginación nuestra precomprensión del nuestro mundo compartido, así como la idea de nosotros mismos. Es más, nuestra capacidad de comunicarnos nos permite pensar los lenguajes como espacios tanto para el sostén de las formas de vida dadas, como para la renovación y para la imaginación de nuevas formas de vida. De manera que la idea y el sentimiento de pertenencia a la humanidad se gestan en el constante ejercicio de la capacidad de juicio que presupone, como acabamos de ver, la imaginación, el sensus communis y el pensamiento representativo. Recordemos con Arendt que

La capacidad de juicio es una habilidad política específica en el propio sentido denotado por Kant, es decir, como habilidad para ver cosas no sólo desde el punto de vista personal sino también según la perspectiva de todos los que estén presentes; incluso ese juicio puede ser una de las habilidades fundamentales del hombre como ser político, en la medida en que le permite orientarse en el ámbito público, en el mundo común. [...] La del juicio es una actividad importante, si no la más importante, en la que se produce este compartir-el-mundo-con-los-demás. ${ }^{40}$

El concepto arendtiano de mundo debe entenderse como el espacio que se constituye en el encuentro constante de los ciudadanos plurales. ${ }^{41}$ El mundo común es un logro político, cuyas raíces están, en efecto, en el hecho de la pluralidad humana, que no se debe confundir con el pluralismo político de las democracias representativas.

\footnotetext{
${ }^{39}$ Hannah Arendt, "Verdad y política", en Entre el pasado y el futuro. Ocho ejercicios sobre la reflexión política (Barcelona: Península, 1996), 254.

${ }^{40}$ Arendt, "Crisis de la cultura su significado político y social" en Entre el pasado... op cit, 233-234.

${ }^{41}$ A veces puede dar la impresión de que Arendt habla sobre el mundo común como si su posibilidad estuviera dada en el hecho ontológico de la pluralidad humana. Y es cierto que, en su libro La Condición Humana, ella tiende a hablar del mundo común como sinónimo de la realidad mundana, entendida como el sentido de objetividad que se genera por la presencia de otras personas que ven lo veo y escuchan lo que oigo, aunque su punto de vista no sea idéntico; sin embargo, el mundo común no está dado. El mundo común es una construcción permanente.
} 
[L]a pluralidad hace referencia a la construcción que hacemos de nosotros mismos por medio de nuestras acciones y discursos, a nuestro esfuerzo deliberado por manifestarnos ante los demás como un "quién" con una historia detrás, no como un "qué". La pluralidad tiene que ver entonces, con la manera en que aparecemos ante un público, y esto supone, ante todo, la voluntad, la iniciativa de querer ser vistos y oídos por los demás. ${ }^{42}$

La pluralidad de la que habla Arendt y que me interesa recuperar no es un dato, es el resultado del esfuerzo comprometido de todos y todas por aparecer en el mundo común de manera singular. El mundo común es un ámbito permeado de diversidad; es más, constituido desde la pluralidad. Esto significa un espacio para la expresión de las identidades diversas y para la comunalidad, y esto, entonces, supone algo más que un espacio de convivencia y tolerancia de individuos distintos.

El mundo común no sólo se construye con diferentes perspectivas expresadas en acciones y discursos, sino también con actos imaginativos de pensar y juzgar que tengan en cuenta la pluralidad. Más aún, es precisamente esta inquietud de formar lazos en común lo que define al mundo, pues no hay mundo en solitario; sólo hay mundo cuando hay pluralidad de participantes que comunican sus juicios. La pluralidad, en tanto condición ontológica de la vida humana, sólo puede aparecer en el mundo común. Nuestra singularidad como individuos, como agentes, no es un dato privado, en algún sentido, oculto; todo lo contrario, requiere de la visibilidad y el reconocimiento que sólo puede darse en el mundo compartido.

Apelar al sensus communis y a la noción de mundo común no nos conduce a defender una suerte de comunidad política unida por un bien común, por una voluntad general; ni mi propuesta ni la arendtiana requieren la supresión de la diversidad en favor de la unidad. Todo lo contrario: se trata de repensar la noción de 'humanidad' desde el concepto de 'pluralidad'. Arendt abre, de este modo, la noción de comunidad de asentimiento más allá de la comunidad cercana. Ella está aludiendo a la humanidad. Somos miembros de la comunidad humana por el hecho de ser humanos, $\mathrm{y}$ esto que constituye nuestra humanidad no es parte de una naturaleza sino fruto de los actos, discursos y juicios de aquellos que nos precedieron, aquellos con los que

\footnotetext{
42 Cristina Sánchez, "Hannah Arendt como pensadora de la pluralidad", Intersticios. Filosofía, Arte,
} Religión, 10, núm. 22/23 (2005), 113. 
compartimos mundo, y aquellos que nos precederán. En este ejercicio va gestándose una comunidad de asentimiento.

Los juicios que nos permiten ganar visibilidad y nos dotan de reconocimiento no pueden ejercerse en solitario, dependen y generan comunicabilidad. Es aquí donde se pone de manifiesto la profunda inquietud humana por acercarse a los demás y reconocerse en ellos como parte de un mundo en común. Más aún, para Arendt es precisamente esta inquietud de formar lazos en común lo que define al mundo [Welt], pues no hay mundo en solitario, no hay mundo en singular, sólo plural y común; sólo hay mundo cuando hay pluralidad de participantes que comunican sus juicios. De manera que, en efecto, "El lazo entre los hombres es, subjetivamente, la 'voluntad de comunicación sin límite' y, objetivamente, el hecho de la comprensión universal". ${ }^{43}$

Así, el cosmopolitismo que me interesa defender no se funda en la validez objetiva de los derechos humanos. Tales derechos no son verdaderos o falsos, son la expresión de prácticas, el ejercicio de capacidades, que abren la posibilidad de coexistir. Esta coexistencia sólo es posible si se reivindica la palabra como forma de acción política. De manera que la interacción se debe articular con la comunicación orientada al entendimiento. En el ejercicio de la comunicación el papel del juicio es fundamental, en tanto no se trata de alcanzar un acuerdo tendente a establecer verdades reconocidas universalmente, sino de extender un modo de habitar el mundo fincado en el ejercicio de la palabra y la acción compartidas.

De esta manera, la capacidad de juicio se torna una herramienta indispensable para la extensión de una cultura, —en el sentido de cultivo_-, de los derechos humanos. Así, el discernimiento, la capacidad de juicio, tendría que entenderse como una forma de hacer señalamientos y reclamaciones que genera acuerdos inestables y siempre en conflicto sobre cuestiones de nos atañen a todos y todas como miembros de la Humanidad. Es más, el permanente debate acerca de diferentes temas de interés común permitiría la ampliación de nuestro sentido de lo que cuenta como una cuestión común. Aquello que es humano, aquello que es asunto de la humanidad no es una cuestión previamente determinada, desde los diferentes márgenes de aquello que hoy consideramos humano emergen teman de

\footnotetext{
${ }^{43}$ Arendt, "Karl Jaspers”, 75 (el énfasis es mío).
} 
debate, análisis y juicio que, a su vez, generan nuestro sentido del mundo común. La humanidad se construye por sus prácticas, a través de las acciones y de los discursos de sus miembros; por su decir y su actuar, conjuntamente. Precisamente por ello, se desarrolla en el ámbito de lo opinable, de lo contingente.

En este sentido, el cosmopolitismo al que apelo es más una práctica que una teoría. Se trata del permanente ejercicio de la capacidad de juicio para posibilitar la coexistencia plena de todos y todas. Esta práctica tiene como guía el llamado arendtiano a respetar el derecho a tener derechos de todas y todos los miembros de la humanidad.

\section{Sobre la humanidad}

Líneas arriba afirmé que el cosmopolitismo es una forma de universalismo. Es un universalismo porque atañe a todos los seres humanos existentes, habidos y por venir. El cosmopolitismo atañe a la humanidad. Ahora bien, la humanidad no puede entenderse como una esencia o naturaleza humana universal; no puede ni debe ser entendida en sentido abstracto sino como el conjunto compuesto por todos y cada uno de los seres humanos concretos que la integran. ${ }^{44}$ Siendo así, los derechos humanos no pueden definirse como una posesión de la que disponemos naturalmente cada uno o una sino el resultado de una práctica, el ejercicio de una capacidad, que reconoce a todos y cada uno de los seres humanos en tanto miembros de la humanidad.

Arendt no desarrolló de manera explícita el concepto de humanidad, pero dejó una serie de ideas acerca del sensus communis y del papel de juicio en política que pueden iluminar el camino. Ésta es la ruta que ha tomado Alessandro Ferrara y en la que, en parte, le acompaño. Este filósofo italiano, en su ensayo "Ejemplaridad y derechos humanos", ${ }^{45}$ nos ofrece unas pistas que pueden ayudarnos a pensar la humanidad no como una fórmula abstracta sino en términos de una "construcción sustantiva". Ferrara

\footnotetext{
${ }^{44}$ Peg Birminghan propone que la idea de Humanidad tiene como raíz el "el anárquico e impredecible evento de natalidad", y es éste el que sirve de fundamento de los derechos humanos. Cfr. Hannah Arendt y los derechos humanos. op. cit. Tal vez podría incluirse a Birminghan entre aquellos que sostienen la necesidad de fundamentos contingentes. En este sentido, ella también apelaría al carácter posfundacionalista de la teoría política arendtiana.

45 "Ejemplaridad y derechos humanos" en La fuerza del ejemplo. Exploraciones del paradigma del juicio (Barcelona, Gedisa, 2008).
} 
establece una distinción entre dos nociones normativas de la humanidad: una moral y otra política. Cuando pensamos la humanidad en términos políticos la concebimos como "una 'sociedad que contiene a todas las otras en su seno' y consideramos las 'sociedades constitutivas' tal cual son realmente, es decir, como las sociedades concretas que conocemos, con su naturaleza, su estructura, su ubicación geográfica, su producto interior bruto, su orden institucional, sus recursos naturales, su historia, etcétera". ${ }^{46}$ Ferrara propone que esta noción de humanidad debe completarse con una concepción más exigente a nivel normativo y sugiere que la entendamos como "el conjunto de todos los seres humanos que han vivido, viven y vivirán en la Tierra" ${ }^{47}$ Así, desde un punto de vista moral nos habla de la realización de la humanidad, tomada como la identidad humana más inclusiva imaginable. ${ }^{48}$ Estoy de acuerdo con esta recuperación del concepto de humanidad; ahora bien, la cuestión entonces es plantearnos qué tipo de identidad supone tal concepto de humanidad, pues no se trata únicamente de un agregado de individuos o de colectividades.

Lo que podemos considerar la "identidad" de la humanidad se construye en lo que Arendt denomina mundo en común. Y éste "no es idéntico a la Tierra o a la Naturaleza, como el limitado espacio para el movimiento de los hombres y la condición general para la vida orgánica". ${ }^{49}$ Este mundo común es el espacio en el que nos movemos unos con otros, nos comportamos y reconocemos recíprocamente. Sin ese reconocimiento la comunidad política no puede existir: "[la] carencia de mundo es siempre una forma de inhumanidad". 50

De modo que, lo común del mundo-en-común no es una concepción general del bien o de lo moral y políticamente correcto que todos tendríamos que compartir, sino

\footnotetext{
${ }^{46}$ Alessandro Ferrara, ibid., 182.

${ }^{47}$ Ibid., 184.

${ }^{48}$ Alessandro Ferrara busca justificar la fuerza normativa de los derechos humanos de manera que supere el dilema existente entre la concepción de los derechos humanos reducidos a derechos positivos en los Estados existentes y las doctrinas morales-filosóficas. Esto es, pretende conciliar pluralismo y universalismo. Según Ferrara, su perspectiva centrada en el paradigma del juicio "nos permite concebir que el universalismo de la justicia se origina en un juicio reflexionante orientado referido a lo que se requiere para el cumplimiento de esa identidad supraordenada (...)". Ibid., 176. (Las cursivas son del autor). Aunque no puedo detenerme en este punto, quiero señalar que no comparto la necesidad de apelar a un universalismo epistémico o moral para justificar la validez de los derechos humanos. Éstos son una práctica cuyo sostén es la noción misma de Humanidad, fruto a su vez de la acción en el espacio público.

49 Arendt, La Condición Humana, 61-62.

${ }^{50}$ Hannah Arendt, "Sobre la humanidad en tiempos de oscuridad. Reflexiones sobre Lessing", en Hombres en tiempos, 23
} 
más bien un espacio creado a partir de la expresión pública de la pluralidad de juicios, de la pluralidad de opiniones. El mundo común es — tomo prestada la expresión de Arendt- "el espacio en el que las cosas se vuelven públicas". ${ }^{51}$ Como bien señala en su texto sobre Lessing:

el mundo no es humano sólo porque está hecho por seres humanos, y no se vuelve humano sólo porque la voz humana resuene en él sino sólo cuando se ha convertido en el objeto de discurso. [...] por mucho que nos afecten las cosas del mundo, por profundo que nos estimulen, sólo se tornan humanas para nosotros cuando podemos discutirlas con nuestros semejantes. [...] Humanizamos aquello que está sucediendo en el mundo y en nosotros mismos con el mero hecho de hablar sobre ello y mientras lo hacemos aprendemos a ser humanos. ${ }^{52}$

En La condición humana, Arendt enfatiza la posibilidad de los agentes políticos de constituirse, al tiempo que constituyen su propio mundo común. En esta construcción conceptos como raza, nación o etnia quedan en un segundo plano. La condición humana de la que nos habla Arendt consiste más bien en una explicación de la génesis de la identidad de los seres humanos, en plural, en el marco del mundo común. Así, nuestra identidad como seres humanos, nuestra humanidad, no es un dato de nuestra historia natural, es un artificio. Tiene que ser pensado como una construcción común en un mundo-en-común que incluye no sólo los individuos actualmente existentes, sino también aquellos que habitaron la Tierra en el pasado, la habitan en el presente y la habitarán en el porvenir. En este sentido, no es un dato, no es un fenómeno que podamos observar, sino el resultado de una praxis cuyo principio de acción fue enunciado por Arendt: el derecho a tener derecho. Es en el ejercicio de este derecho que la humanidad se hace posible. Por ello, desde esta perspectiva, no puede caracterizarse remitiéndonos a una naturaleza o esencia humana.

Nótese que, como dijimos líneas atrás, la humanidad no es un mero agregado de sociedades ni de individualidades. ¿Cuál es el nexo, el vínculo que relaciona a los sujetos que integran la humanidad? En respuesta a esta cuestión, es importante enfatizar que el nexo entre los miembros de una comunidad no es, para Arendt, ni la caridad ni la

\footnotetext{
${ }^{51}$ Citada por Linda Zerilli, "Value Pluralism and the Problem of Judgment: Farewell to Public Reason", en Political Theory, (2012), 6.

${ }^{52}$ Arendt, "Sobre la humanidad...", 35 (el énfasis es mío). 
fraternidad heredadas del pensamiento cristiano, sino el respeto mutuo o la concordia que los sujetos desarrollan al tomar conciencia de que comparten un mundo común. La relación de respeto mutuo, será — en tanto condición de posibilidad de la vida en la Tierra - el principio de cohesión de la comunidad humana. Ahora bien, no debemos confundir esta noción de concordia - que Arendt recupera en La condición humana de Aristóteles a través de la noción de philia política o amistad cívica- con la idea de la fraternidad cristiana. En el texto que Arendt dedica a Lessing, así como en Sobre de la revolución, la filósofa se encarga de distinguir muy bien estos dos rubros. Para ella, es importante diferenciar con claridad entre la amistad moderna dominada por el eros y la amistad antigua caracterizada por la philia:

los antiguos consideraban que los amigos eran indispensables para la vida humana, que una vida sin amigos no valía la pena de ser vivida... [Actualmente] [e]stamos acostumbrados a ver la amistad como un fenómeno de intimidad, donde los amigos abren sus corazones sin tener en cuenta el mundo y sus demandas. [...] Por lo tanto, nos resulta difícil comprender la importancia política de la amistad. ${ }^{53}$

Entendida como eros destruye la posibilidad de construir un espacio público de las identidades diversas, plurales. Precisamente en su trabajo sobre Lessing, Arendt critica esta búsqueda de intimidad, porque significa evitar la disputa, tratar sólo con personas con las que no se entra en conflicto. La excesiva cercanía, según Arendt, suprime las distinciones, elimina el mundo compartido que es por definición un espacio para la pluralidad.

En La condición humana ya había dicho que "[e]l amor, debido a su pasión, destruye el en medio de que nos relaciona y nos separa de los demás". ${ }^{54}$ Es la noción de respeto mutuo, más cercana a la tradición kantiana ${ }^{55}$ la que puede ayudarnos a comprender nuestra inserción en un mundo común, compartido. El respeto mutuo es el

\footnotetext{
53 Arendt, Hombres en tiempos, 34.

${ }^{54}$ Arendt, La condición humana, 261.

55 El vínculo de la amistad cívica con la capacidad de discernimiento me permite ofrecer una lectura de Arendt alejada del neo-aristótelismo. Es cierto que el libro La condición humana (Vita activa en la versión alemana de 1960) supuso un debate en Alemania caracterizado por el redescubrimiento de la actualidad del pensamiento ético y político de Aristóteles y con ello, la aparición de posturas neo-aristotélicas. Efectivamente Arendt compartiría con este planteamiento la intención de rescatar la acción del hombre de la cosificación padecida en la época moderna y el rechazo a las concepciones positivistas de la filosofía política para comprender la acción humana. Sin embargo, ella rechaza claramente la recuperación de una dimensión normativa tanto en las actuaciones éticas como políticas.
} 
principio moral desde el cual es posible apelar al derecho a tener derechos. Recordemos que la condición ontológica para la acción y el discurso, indispensable para construir un mundo en común, es la pluralidad. Habitar el mundo significa compartirlo con otros que ya estaban ahí en el momento de nuestro nacimiento y que percibimos como, en parte, iguales y fundamentalmente distintos. En palabras de Arendt, la pluralidad "tiene el doble carácter de igualdad y de distinción". ${ }^{56}$ El mundo que construimos con nuestras acciones y nuestros actos a partir de nuestra condición de seres plurales es común a todos por el solo hecho de habitarlo, pero requerimos de la política para mantenerlo, consolidarlo y legarlo a los que vendrán. De manera que la pluralidad, condición ontológica propia de los seres humanos, es la condición de la que partimos en nuestra inserción en el mundo y, podemos decir, en la constitución de la humanidad. "La pluralidad es la ley de la Tierra", ${ }^{57}$ nos dice Arendt. Esta condición no debe confundirse con la alteridad (otherness, es el término utilizado por Arendt); los seres humanos no somos únicamente ejemplares de una misma especie. Los seres humanos somos seres "únicos" pues cada nacimiento pone en el mundo un ser único que antes no existía y que no puede ser reemplazado por otro. Y esto es así, por nuestra condición de seres libres. La libertad es "inherente al ser humano en cuento criatura viviente que nace y que muere". ${ }^{5}$ Cada nacimiento hace posible un nuevo inicio, una nueva cadena de acontecimientos no predeterminados, sino abiertos a las elecciones de ese ser nuevo que es fundamentalmente un agente libre. De manera que los seres humanos llegamos a un mundo cuya existencia nos precede y que permanecerá tras nuestra muerte, y es un mundo que depende de nuestras palabras y nuestras acciones en el presente. Es interesante notar que cada vez que actuamos o nos pronunciamos sobre lo que acontece en el mundo, que además percibimos como distinto de nosotros, estamos constituyéndolo y con ello conformando nuestra identidad como humanidad. Ese mundo en común, que percibimos ajeno y propio simultáneamente, es el que nos permite orientar nuestra existencia en la Tierra. Nótese, entonces que no debe confundirse el mundo con el planeta Tierra ni con la naturaleza; el

\footnotetext{
${ }^{56}$ Arendt, La condición humana, 200

${ }^{57}$ Arendt, La vida del Espíritu. El pensar, la voluntad y el juicio en la filosofía y en la política (Madrid: Centro de Estudios Constitucionales, 1984), 31

${ }^{58}$ Antonio Campillo, "Espacios de aparición: el concepto de lo político en Hannah Arendt", Daimon, núm 26 (2002), 164.
} 
mundo es el conjunto de cosas, discursos, artefactos, narraciones, instituciones que los seres humanos hemos ido creando en nuestro paso por la Tierra. Hannah Arendt nos dice al respecto que "siempre que se juntan los hombres — sea privada, social o públicopolíticamente surge entre ellos un espacio que los reúne y a la vez los separa". ${ }^{59}$ Éste es nuestro mundo en común. Y en la cohabitación en él, en la praxis y actualización permanente de nuestra humanidad, se requiere del respeto mutuo que abre la posibilidad de comprensión y de entendimiento en un mundo preñado de pluralidad.

\section{Conclusión}

A lo largo de estas líneas, he buscado poner de manifiesto que el 'derecho a tener derechos' es un llamado a colocar en primer término la capacidad de existir, de ser en el mundo común constituido y compartido por todos y todas. La carencia del derecho a tener derechos se manifiesta, como bien señaló Arendt, en la privación de un lugar en el mundo que haga significativas las opiniones y efectivas las acciones; por ello, desde su pensamiento, he defendido la existencia de un derecho político fundamental de todo ser humano, el derecho a tener derechos. Éste consiste en la demanda de ser reconocido por otros como persona merecedora de respeto y, además, acreedora de derechos legalmente garantizados en el seno de una comunidad humana. Y no sólo esto, sino que, si entendemos el derecho como una capacidad, como poder - y no únicamente como ley-, se pone de manifiesto que el derecho a tener derechos es un llamado a poner en primer término la capacidad de existir, de coexistir.

He revisado el dictum arendtiano para defender que es posible conceptualizar los derechos desde su radical contingencia, y por ello, sin necesidad de apelar a fundamentos metafísicos o epistémicos. Considero que el dictum arendtiano nos abre a una noción de la condición humana articulada en torno a aquello que le es más propio: la capacidad de actuar con los otros para la construcción de un ámbito para la vida en común. Y es la capacidad de juicio el elemento que nos permite reconciliar nuestro ideal político de existencia cosmopolita con nuestra existencia concreta. Se trata de una reconciliación con

\footnotetext{
${ }^{59}$ Hannah Arendt, ¿Qué es la política? (Barcelona: Paidós, 1997), 57. 
la realidad, con el mundo al que cada uno llega por su nacimiento. Dicha reconciliación está guiada por una confianza en que los hombres, en plural, pueden alcanzar el sentido de la existencia mediante la comprensión individual de los acontecimientos, la acción en concierto y la experiencia de la palabra.

Dada esta caracterización del derecho humano fundamental a tener derechos, he argumentado a favor de una concepción del cosmopolitismo que no requiere postular fundamentos a priori. La defensa de un concepto de humanidad como construcción común concreta y la idea de comunidad de asentimiento me han permitido sostener que es la participación, desde la pluralidad, la que nos permite definir derechos y obligaciones de los ciudadanos del mundo, es decir, sobre la base de la reciprocidad y el reconocimiento y respeto mutuo y no a partir de una pertenencia. Se trata de enfatizar, como hizo Hannah Arendt, la posibilidad de los seres humanos de constituirse, al tiempo que constituyen su propio mundo común. Esta caracterización de la idea de humanidad no implica renunciar a la fuerza moral y política del concepto; todo lo contrario, se trata de dotarle de su sentido pleno, evitando la reducción de este concepto a un principio de corte metafísico que se coloca fuera de la política, de la práctica y del ejercicio de la acción y la palabra. La humanidad no es un fenómeno natural ni una abstracción metafísica, es una construcción que demanda de todos y cada uno de los seres humanos un esfuerzo y un compromiso de respeto mutuo. De esta manera, el cosmopolitismo que sostengo es una práctica política de aplicación universal que supone y debería reflejarse en un orden político y jurídico cuya validez se sostiene en el ejercicio de la capacidad de juicio de los miembros de la comunidad humana.

Sólo desde estos presupuestos podremos hilvanar un cosmopolitismo de orden jurídico político orientado por un ideal de una existencia cosmopolita. Dicho cosmopolitismo no se sustentaría en una concepción de la identidad natural o esencial de sus miembros, sino en una noción de identidad cosmopolita gestada por la práctica del juicio crítico acerca de aquellos asuntos que nos competen a todos. Así, mi propuesta de un cosmopolitismo sin fundamentos últimos extrapolíticos, parte de la constatación de que la política, tanto en el ámbito nacional como internacional, despojada de la pluralidad de los agentes, supone la renuncia a todo aquello que los vinculaba como seres participantes de un 
mundo en común. Los ciudadanos hemos sido exiliados de nuestra capacidad para juzgar, de nuestra habilidad para crear horizontes de comprensión que son los que nos permiten discernir lo correcto de lo incorrecto. El sentido de pertenencia, el sentido de mundo común se ha desviado de nuestra condición de ser humanos en un mundo compartido a ser ciudadanos de pleno derecho de un Estado determinado. Se trata de recuperar el verdadero sentido de los derechos como prácticas de construcción de la humanidad. Entendida como construcción común, la humanidad requiere que hagamos algo en relación con las diferencias empíricas que, de hecho, existen entre nuestras comunidades, y esto que podemos hacer depende del ejercicio de nuestra capacidad de juicio en la acción política, en la práctica de los derechos. La interpretación del derecho, su ampliación, el intercambio de argumentos nos permitiría abrirnos a la comprensión de las diferencias. Dicha apertura es la que delimita, ensancha o estrecha el concepto de 'humanidad'.

El concepto de cosmopolitismo sin fundamentos últimos que he apuntado aquí constituye un intento de ensanchar y modificar cualitativamente la noción de 'comunidad de ciudadanos' en sentido cosmopolita. En efecto, el cosmopolitismo es un llamado a ser y existir como conciudadanos, como ciudadanos del mundo. Un mundo que es el fruto siempre inestable, permanentemente en proceso, de la trama de las relaciones humanas establecida a través de las acciones y las palabras y por medio de la multiplicidad de juicios que articulan una comunidad de asentimiento. 


\section{Bibliografía}

Arendt, Hannah. “The Rights of Man: What Are They?”. Modern Review, 3, núm. 1 (1949): 24-36.

Arendt, Hannah. La vida del espíritu. El pensar, la voluntad y el juicio en la filosofía y en la política. Madrid: Centro de Estudios Constitucionales, 1984.

Arendt, Hannah. Hombres en tiempos de oscuridad. Barcelona: Gedisa, 1990.

Arendt, Hannah. “Karl Jaspers ¿Ciudadano del mundo?”. En Hombres en tiempos de oscuridad. Barcelona: Gedisa, 1990.

Arendt, Hannah. "La humanidad en tiempos de oscuridad. Reflexiones sobre Lessing". En Hombres en tiempos de oscuridad. Barcelona: Gedisa, 1990.

Arendt, Hannah. "Crisis de la cultura su significado político y social". En Entre el pasado y el futuro. Ocho ejercicios sobre la reflexión política. Barcelona: Península, 1996.

Arendt, Hannah. "Verdad y política". En Entre el pasado y el futuro. Ocho ejercicios sobre la reflexión política. Barcelona: Península, 1996.

Arendt, Hannah. ¿Qué es la política? Barcelona: Paidós, 1997.

Arendt, Hannah. "Pensamientos sobre política y revolución. Un comentario". En Crisis de la república. Madrid: Taurus, 1998.

Arendt, Hannah. Los orígenes del totalitarismo, vol. II. Madrid: Alianza Editorial, 1998.

Arendt, Hannah. La condición humana, int. Manuel Cruz, $3^{\mathrm{a}}$ reimpr. Barcelona: Paidós, 1998.

Arendt, Hannah. Conferencias sobre la filosofía política de Kant, int. y ed. Ronald Beiner. México: Paidós, 2003.

Arendt, Hannah. Eichmann en Jerusalén. Un estudio sobre la banalidad del mal. Barcelona: Lumen, 2003.

Arendt, Hannah. “La Nación”. En Ensayos de comprensión 1930-1954 (255-260), trad. Agustín Serrano de Haro. Madrid: Caparrós Editores, 2005. 
Balibar, Étienne. "Impolítica de los derechos humanos. Arendt, el 'derecho a tener derechos' y la desobediencia cívica”. Erytheis, núm. 2 (noviembre, 2007): 6. http://idt.uab.es/erytheis/balibar_es.htm.

Benhabib, Seyla. Los derechos de los otros. Extranjeros, residentes, ciudadanos. Barcelona: Gedisa, 2005.

Benhabib, Seyla. "Otro universalismo: sobre la unidad y diversidad de los derechos humanos". Isegoría (diciembre, 2008): 175-203.

Benhabib, Seyla. Exile, Statelessness, and Migration: Playing Chess with History from Hannah Arendt to Isaiah Berlin. Princeton, NJ: Princeton University Press, 2018.

Bernstein, Richard. "Hannah Arendt: The Ambiguities of Theory and Practice". En Terrence Ball (ed.), Political Theory and Praxis: New Perspectives. Minneapolis, MN: University of Minnesota Press, 1977.

Bernstein, Richard. "Provocation and Appropriation: Hannah Arendt's Response to Martin Heidegger". Constellations, 4, núm. 2 (1997).

Birmingham, Peg. Hannah Arendt y los derechos humanos. El dilema de la responsabilidad común. Buenos Aires: Prometeo, 2017.

Campillo, Antonio. "Espacios de aparición: el concepto de lo político en Hannah Arendt”. Daimon, núm. 26 (2002): 159-186.

Cruz Parcero, Juan Antonio. "Derecho subjetivo”. En Carlos Pereda (ed.), J. Marcone, M. T. Muñoz y S. Ortiz (coords.), Diccionario de Justicia (150-155). México: Siglo XXI, 2017.

Di Pego, Anabella. "Hacia una política posfundacional: reconsideraciones en torno de la revolución, la fundación y el poder en Hannah Arendt”. En Marco Estrada y María Teresa Muñoz (comp.), Violencia y revolución en la filosofía de Hannah Arendt. Reflexiones críticas, 105-140. México: El Colegio de México, 2015.

Ferrara, Alessandro. La fuerza del ejemplo. Exploraciones del paradigma del juicio. Barcelona: Gedisa, 2008.

Hilb, Claudia. “El principio del initium”. En Marco Estrada y María Teresa Muñoz (comp.), Violencia y revolución en la filosofía de Hannah Arendt, 67-102. México: El Colegio de México, 2015. 
Lefort, Claude. Democracy and Political Theory. Minneapolis, MN: Universidad de Minnesota Press, 1988.

Marchart, Oliver. El pensamiento político posfundacional. La diferencia política en Nancy, Lefort, Badiou y Laclau. México: Fondo de Cultura Económica, 2009.

Muñoz, María Teresa. "El retorno de lo político. Acerca de la oposición entre poder y violencia”. En Armando Casas y Leticia Flores (comps.), Relatos de violencia. Acercamientos desde la filosofía, la literatura y el cine. México: Facultad de Filosofía y Letras, UNAM / Centro Universitario de Estudios Cinematográficos, UNAM, 2013.

Muñoz, María Teresa. "Violencia y revolución. Reflexiones en torno a lo político". En Marco Estrada y María Teresa Muñoz (comp.), Violencia y revolución en la filosofía de Hannah Arendt. Reflexiones críticas, 305-340. México: El Colegio de México, 2015.

Muñoz, María Teresa. “Ciudadanía, Estado-nación y derechos humanos. Una revisión crítica desde el pensamiento arendtiano”. En Luis González Placencia (coord.), Los derechos humanos de los márgenes al centro. Discusiones sobre ciudadanía, política y derechos, vol. 2. Tlaxcala: Ubijus / Universidad de Tlaxcala, 2020.

Muñoz, María Teresa. "Ciudadanía y derechos”. Revista UIC Foro Multidisciplinario de la Universidad Intercontinental (octubre-diciembre, 2017).

Owens, Patricia. "Walking Corpses: Arendt on the Limits and the Possibilities of Cosmopolitan Politics". En Cerwyn Moore y Chris Farrands (eds.), International Relations Theory and Philosophy: Interpretive Dialogues. Londres: Routledge, 2010.

Posenti, Ilaria. L'apolide e il paria. Lo straniero nella filosofia di Hannah Arendt. Roma: Carocci Editore, 2002.

Sánchez, Cristina. "Hannah Arendt como pensadora de la pluralidad". Intersticios. Filosofía, Arte, Religión, 10, núm. 22/23 (2005): 115-116.

Tassin, Étienne. "Hannah Arendt frente a la globalización”. En Julia Smola, Claudia Bacci y Paula Hunziker (eds.), Lecturas de Arendt. Diálogos con la literatura, la filosofía y la política, 207-220. Córdoba, Argentina: Editorial Brujas, 2012. 
Tassin, Étienne. Le Trésor perdu, Hannah Arendt l'intelligence de l'action politique. París: Payot \& Rivages, 1999.

Villa, Dana. Politics, Philosophy, Terror. Princeton, NJ: Princeton University Press, 1999.

Zerilli, Linda. "The Practice of Judgment: Hannah Arendt's Copernican Revolution". En Jane Elliott and Dereck Atridge (eds.), Theory after Theory. Londres: Routledge, 2011.

Zerilli, Linda. "Value Pluralism and the Problem of Judgment: Farewell to Public Reason”. Political Theory, 40, núm. 1 (2012): 6-31. 